\title{
BMJ Open Association between meteorological factors and audiogram configurations in patients with sudden sensorineural hearing loss: a cross-sectional study
}

\author{
Jilei Zhang, ${ }^{1}$ Shangwei $\mathrm{Ji}^{2}{ }^{2}$ Xin Ma, ${ }^{1}$ Lisheng Yu, ${ }^{1}$ Yuanyuan Jing (D) ${ }^{1}$
}

To cite: Zhang J, Ji S, Ma X, et al. Association between meteorological factors and audiogram configurations in patients with sudden sensorineural hearing loss: a cross-sectional study. BMJ Open 2021;11:e045768. doi:10.1136/ bmjopen-2020-045768

- Prepublication history for this paper is available online. To view these files, please visit the journal online (http://dx.doi. org/10.1136/bmjopen-2020045768).

Received 11 October 2020 Accepted 12 November 2021

Check for updates

(c) Author(s) (or their employer(s)) 2021. Re-use permitted under CC BY-NC. No commercial re-use. See rights and permissions. Published by BMJ.

${ }^{1}$ Otorhinolaryngology Department, Peking University People's Hospital, Beijing, China ${ }^{2}$ Beijing Jishuitan Hospital, Beijing, China

Correspondence to Dr Yuanyuan Jing; 15811398082@163.com

\section{ABSTRACT}

Objective We aimed to determine the association between meteorological factors and sudden sensorineural hearing loss (SSNHL) audiogram configurations.

Design Retrospective review of medical records from 1 October 2007 to 31 December 2018.

Setting A tertiary hospital.

Participants 510 patients with SSNHL who had data on the exact date of SSNHL onset and underwent audiological evaluation within 14 days were included.

Primary and secondary outcome measures Daily values of meteorological factors, including maximum and minimum temperature, mean temperature and its dayto-day change, diurnal temperature range, atmospheric pressure, mean and maximum wind speed and relative humidity, and seasonal distributions.

Results Among the 510 patients (259 women (50.8\%); mean (SD) age, 46.4 (15.5) years), 108 (21.2\%) displayed ascending patterns, $143(28.0 \%)$ displayed descending patterns, $129(25.3 \%)$ displayed flat patterns and 130 $(25.5 \%)$ displayed profound patterns of audiograms. The diurnal temperature range on the day of SSNHL onset in patients with profound patterns was significantly higher than that in patient with ascending (mean difference (MD), $2.2^{\circ} \mathrm{C} ; 95 \% \mathrm{Cl}, 0.7^{\circ} \mathrm{C}$ to $3.7^{\circ} \mathrm{C} ; \mathrm{p}=0.001$ ) and descending (MD, $1.5^{\circ} \mathrm{C} ; 95 \% \mathrm{Cl}, 0.1^{\circ} \mathrm{C}$ to $2.9^{\circ} \mathrm{C} ; \mathrm{p}=0.031$ ) patterns. The relative humidity was the highest on the day of SSNHL onset in patients with ascending patterns and showed a significant difference compared with that in patients with profound patterns (MD, 8.0\%; $95 \% \mathrm{Cl}, 0.7 \%$ to $15.3 \%$; $\mathrm{p}=0.026$ ). Seasonal distribution did not differ among patients with different audiogram configurations.

Conclusions Profound audiogram patterns correlated with high diurnal temperature range, while ascending audiogram patterns correlated with high relative humidity in patients with SSNHL. No correlation was observed between seasons and audiogram configurations.

\section{INTRODUCTION}

Sudden sensorineural hearing loss (SSNHL) is an otological emergency defined as hearing loss occurring over a relatively short period of time with no identifiable cause. SSNHL affects 5-27 individuals per 100000 people annually, with approximately 66000 new cases per year in the USA alone. ${ }^{1}$ Although various theories
Strengths and limitations of this study

- Meteorological factors are associated with the incidence and prognosis of sudden sensorineural hearing loss (SSNHL); however, there are limited data on its correlation with audiogram configurations of SSNHL.

- This study included patients diagnosed with SSNHL within 14 days after SSNHL onset to mitigate recall bias from the retrospective design.

- This study was conducted at a single tertiary hospital that receives patients from all over the country.

have been proposed, such as vascular impairment, viral infection, rupture of the labyrinth membrane and immune-mediated disorder, the aetiology of SSNHL is unclear. ${ }^{2-4}$

Vascular impairment is a widely accepted theoretical mechanism for SSNHL. The inner ear is supplied by the labyrinthine artery, which is a functional end artery that terminates in two branches supplying the cochlea and vestibular organ. The cochlea is susceptible to ischaemic injury through various vascular insults, such as thromboembolism or vasospasm. ${ }^{5}$ Further, shunting from the periphery cannot compensate for disturbances in the blood supply to the cochlea because the labyrinthine artery is a terminal artery and is positioned intraosseously. Animal models have shown that impairment in microcirculation of the cochlea leads to immediate loss of function of the organ of Corti. ${ }^{6}$ Moreover, the clinical characteristics of SSNHL are similar to those of other ischaemic vascular diseases ${ }^{7}$ - symptoms develop abruptly without any preceding signs and only one side of the ear is affected in general. Many studies have reported that diseases of vascular origin, such as acute myocardial infarction, ${ }^{8}$ stroke $^{9}$ and migraine, ${ }^{10}$ are correlated with meteorological factors. However, studies have 
drawn inconsistent conclusions regarding the correlation between SSNHL and meteorological factors.

The audiogram configuration of SSNHL can be categorised into five distinct patterns: ascending, descending, flat, profound and others. ${ }^{11}$ Each audiogram pattern is considered to be the result of different pathogenetic mechanisms. ${ }^{12}$ This study aimed to investigate the association between meteorological factors and different audiogram configurations of SSNHL.

\section{PATIENTS AND METHODS}

\section{Study population}

This retrospective cross-sectional study included patients who were diagnosed with SSNHL at the Otorhinolaryngology Department in our hospital between 1 October 2007 and 31 December 2018. The diagnostic criteria for SSNHL were unexplained hearing loss of $\geq 30 \mathrm{~dB}$ at more than three consecutive pure-tone frequencies occurring within a 72-hour period. Patients who underwent audiological evaluation within 14 days of SSNHL onset were included. Patients with known causes of hearing loss, including middle ear disease, Ménière's disease, acoustic neuroma and large vestibular aqueduct syndrome, were excluded. The medical records of all patients were thoroughly reviewed. Data on demographics, clinical parameters and date and geographical location of SSNHL attacks were collected. Laboratory results at the time of hospital admission were recorded, including complete blood count, coagulation panel and biochemical test results. All patients were treated with intravenous steroids (methylprednisolone $40 \mathrm{mg} /$ day) for 5 days. Patients who did not achieve complete recovery received intratympanic steroids (methylprednisolone $20 \mathrm{mg}$ every 2 days) on days $6,8,10,12$ and 14 in different combinations with blood flow-promoting drugs, vasodilators, vitamins and diuretics. Written informed consent that authorised the use of personal medical data in the study was obtained from all patients. The study was conducted in accordance with the Declaration of Helsinki.

\section{Auditory evaluation}

Pure-tone audiometry was performed on the day of inclusion and at the end of treatment on the 14th day. The pure-tone average was calculated from the air conduction thresholds at 500,1000, 2000 and $4000 \mathrm{~Hz}$ in the affected ear. Initial audiogram configurations were classified as ascending (the average threshold of $250-500 \mathrm{~Hz}$ was $20 \mathrm{~dB}$ higher than $4-8 \mathrm{kHz}$ ), descending (the average threshold of $4-8 \mathrm{kHz}$ was $20 \mathrm{~dB}$ higher than $250-500 \mathrm{~Hz}$ ), flat (similar threshold across the entire frequency range) and profound (flat configuration with hearing threshold $>90 \mathrm{~dB}$ ) patterns. The level of recovery was evaluated according to Siegel's criteria as follows: (1) complete recovery: final hearing $<25 \mathrm{~dB}$, (2) partial recovery: $>15 \mathrm{~dB}$ gain and final hearing 25-45 dB, (3) slight improvement: $>15 \mathrm{~dB}$ gain and final hearing $>45 \mathrm{~dB}$; and (4) no improvement: $<15 \mathrm{~dB}$ gain and final hearing $>75 \mathrm{~dB}$. The overall recovery is the sum of complete recovery, partial recovery and slight improvement.

\section{Meteorological data}

According to the date and geographical location of SSNHL attacks, meteorological data on daily maximum and minimum temperature, daily mean temperature and its day-to-day change, diurnal temperature range, atmospheric pressure, mean and maximum wind speed and relative humidity were obtained from the National Climatic Data Center (http://www.ncdc.noaa.gov/). Seasons were defined as spring (1 March-31 May), summer (1 June-31 August), autumn (1 September-30 November) and winter (1 December-28/29 February).

\section{Statistical analysis}

Categorical variables are presented as frequencies and percentages, and continuous variables are presented as mean \pm SD. Meteorological factors were compared between the different audiogram patterns using oneway analysis of variance with the Scheffé post hoc test. Comparisons of clinical characteristics and recovery rate between the profound and non-profound groups were performed using unpaired t-test and the Pearson $\mathrm{X}^{2}$ test or Fisher's exact test, as appropriate. Effective sizes and 95\% CIs were presented to describe the magnitude of the differences between the groups. The level of statistical significance was set at a two-tailed $p$ value of $<0.05$. All statistical analyses were performed using SPSS software (V.24.0) and GraphPad Prism software V.7.0.

\section{Patient and public involvement}

It was not appropriate or possible to involve patients or the public in the design, conduct, reporting or dissemination plans of our research.

\section{RESULTS}

Among the 510 patients (259women (50.8\%); mean (SD) age, 46.4 (15.5) years) who met the inclusion criteria, $108(21.2 \%)$ displayed ascending audiogram patterns, $143(28.0 \%)$ displayed descending patterns, $129(25.3 \%)$ displayed flat patterns and 130 (25.5\%) displayed profound patterns. Each meteorological factor on the day of SSNHL onset was analysed. Only the diurnal temperature range and relative humidity showed significant correlations with specific audiogram configurations (table 1). The average diurnal temperature range on the day of SSNHL onset in patients with profound patterns was significantly higher than that in patients with ascending (mean difference (MD), $2.2^{\circ} \mathrm{C} ; 95 \% \mathrm{CI}, 0.7^{\circ} \mathrm{C}$ to $3.7^{\circ} \mathrm{C}$; $\mathrm{p}=0.001)$ and descending $\left(\mathrm{MD}, 1.5^{\circ} \mathrm{C} ; 95 \% \mathrm{CI}, 0.1^{\circ} \mathrm{C}\right.$ to $2.9^{\circ} \mathrm{C} ; \mathrm{p}=0.031$ ) patterns. The diurnal temperature range on the day of SSNHL onset was higher in patients with profound patterns than in those with flat patterns, but the difference was not statistically significant (figure 1A). The relative humidity was the highest on the day of SSNHL onset in patients with ascending patterns and showed a 
Table 1 Comparison of meteorological factors and seasonal distribution between different audiogram configurations

\begin{tabular}{|c|c|c|c|c|c|}
\hline Variables & Ascending $(n=108)$ & Descending $(n=143)$ & Flat $(n=129)$ & Profound $(n=130)$ & $P$ value \\
\hline $\begin{array}{l}\text { Maximum temperature, } \\
\text { mean (SD), }{ }^{\circ} \mathrm{C}\end{array}$ & $19.6(11.2)$ & $18.1(12.2)$ & $19.5(11.7)$ & $19.4(11.8)$ & 0.683 \\
\hline $\begin{array}{l}\text { Mean temperature, mean } \\
\text { (SD), }{ }^{\circ} \mathrm{C}\end{array}$ & $14.8(11.1)$ & $13.0(11.8)$ & $14.2(11.2)$ & $13.7(11.9)$ & 0.649 \\
\hline $\begin{array}{l}\text { Diurnal temperature } \\
\text { range, mean (SD), }{ }^{\circ} \mathrm{C}\end{array}$ & $8.9(3.7)$ & $9.6(4.1)$ & $10.1(4.2)$ & $11.1(4.1)$ & 0.000 \\
\hline $\begin{array}{l}\text { Atmosphere pressure, } \\
\text { mean (SD), hPa }\end{array}$ & $1006.9(20.7)$ & $1007.9(23.1)$ & $1005.2(30.0)$ & $1006.6(23.5)$ & 0.841 \\
\hline $\begin{array}{l}\text { Relative humidity, mean } \\
\text { (SD), \% }\end{array}$ & $58.9(21.1)$ & 55.7 (19.9) & $54.5(19.8)$ & $50.9(19.3)$ & 0.022 \\
\hline Seasons, n (\%) & & & & & 0.161 \\
\hline Spring & $21(19.4)$ & $44(30.8)$ & $32(24.8)$ & $34(26.2)$ & \\
\hline Summer & $29(26.9)$ & $22(15.4)$ & $32(24.8)$ & 35 (26.9) & \\
\hline Autumn & $25(23.1)$ & $30(21.0)$ & $21(16.3)$ & $30(23.1)$ & \\
\hline Winter & $33(30.6)$ & 47 (32.9) & $44(34.1)$ & $31(23.8)$ & \\
\hline
\end{tabular}

significant difference compared with that in patients with profound patterns (MD, $8.0 \% ; 95 \% \mathrm{CI}, 0.7 \%$ to $15.3 \%$; $\mathrm{p}=0.026$; figure $1 \mathrm{~B})$. In addition, there was no significant difference in seasonal distribution among the four pattern groups (table 1).

The percentage of patients aged $>60$ years (MD, $19.6 \% ; 95 \% \mathrm{CI}, 10.5 \%$ to $29.2 \% ; \mathrm{p}=0.000)$, those with vertigo (MD, $28.0 \%$; $95 \% \mathrm{CI}, 18.1 \%$ to $37.3 \%$; $\mathrm{p}=0.0 .000$ ), those with diabetes (MD, 8.7\%; $95 \% \mathrm{CI}, 1.6 \%$ to $17.1 \%$; $\mathrm{p}=0.014)$, those with stroke (MD, $3.9 \% ; 95 \% \mathrm{CI}, 0.2 \%$ to $9.7 \% ; \mathrm{p}=0.047)$ and those with coronary artery disease (MD, $7.3 \%$; $95 \%$ CI, $2.3 \%$ to $14.1 \%$; $\mathrm{p}=0.002$ ) was significantly higher in the group with profound patterns than in the other groups. The mean prothrombin time (MD, $-0.6 \mathrm{~s} ; 95 \% \mathrm{CI},-1.2$ to $-0.1 \mathrm{~s} ; \mathrm{p}=0.006)$ was significantly shorter and the mean concentration of fibrinogen (MD, $19.5 \mathrm{mg} / \mathrm{dL} ; 95 \% \mathrm{CI}, 1.8$ to $40.8 \mathrm{mg} / \mathrm{dL} ; \mathrm{p}=0.008$ ) was significantly higher in the group with profound patterns than in the other groups (table 2).

Response to treatment in 373 patients who underwent pure-tone audiometry on the 14th day after therapy was measured. The overall recovery rate was significantly lower in the group with profound patterns than in other groups (MD, $-11.8 \%$; $95 \% \mathrm{CI},-21.9 \%$ to $-1.1 \%$; $\mathrm{p}=0.031$; table 3).
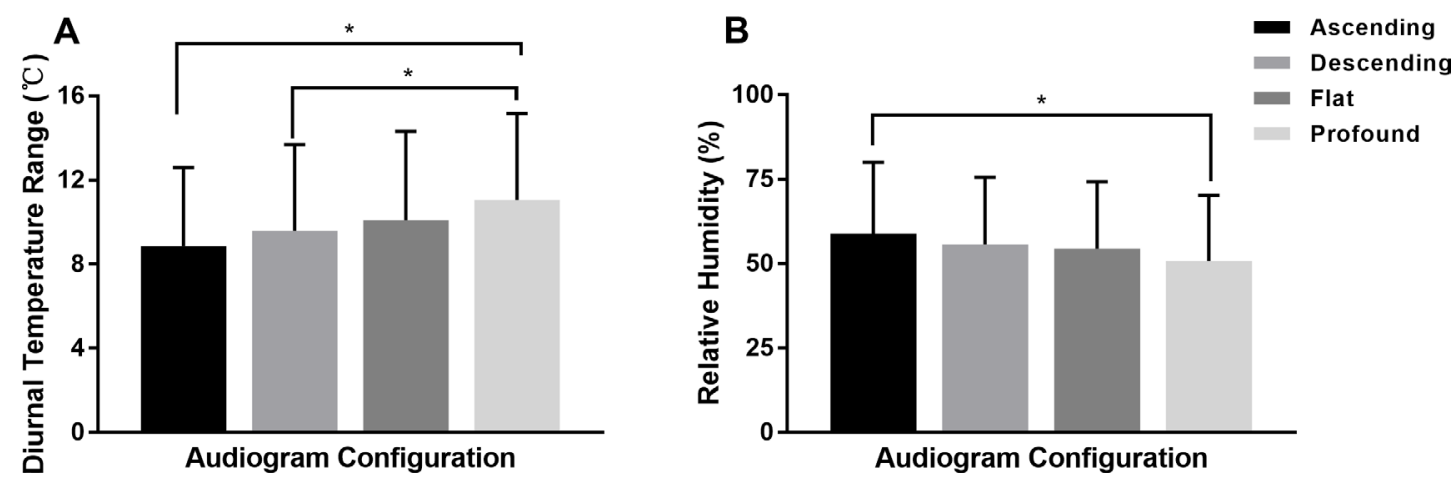

Figure 1 (A) Comparison of the diurnal temperature range between different audiogram configurations. (B) Comparison of relative humidity between different audiogram configurations. 
Table 2 Clinical characteristics of patients with profound and non-profound patterns

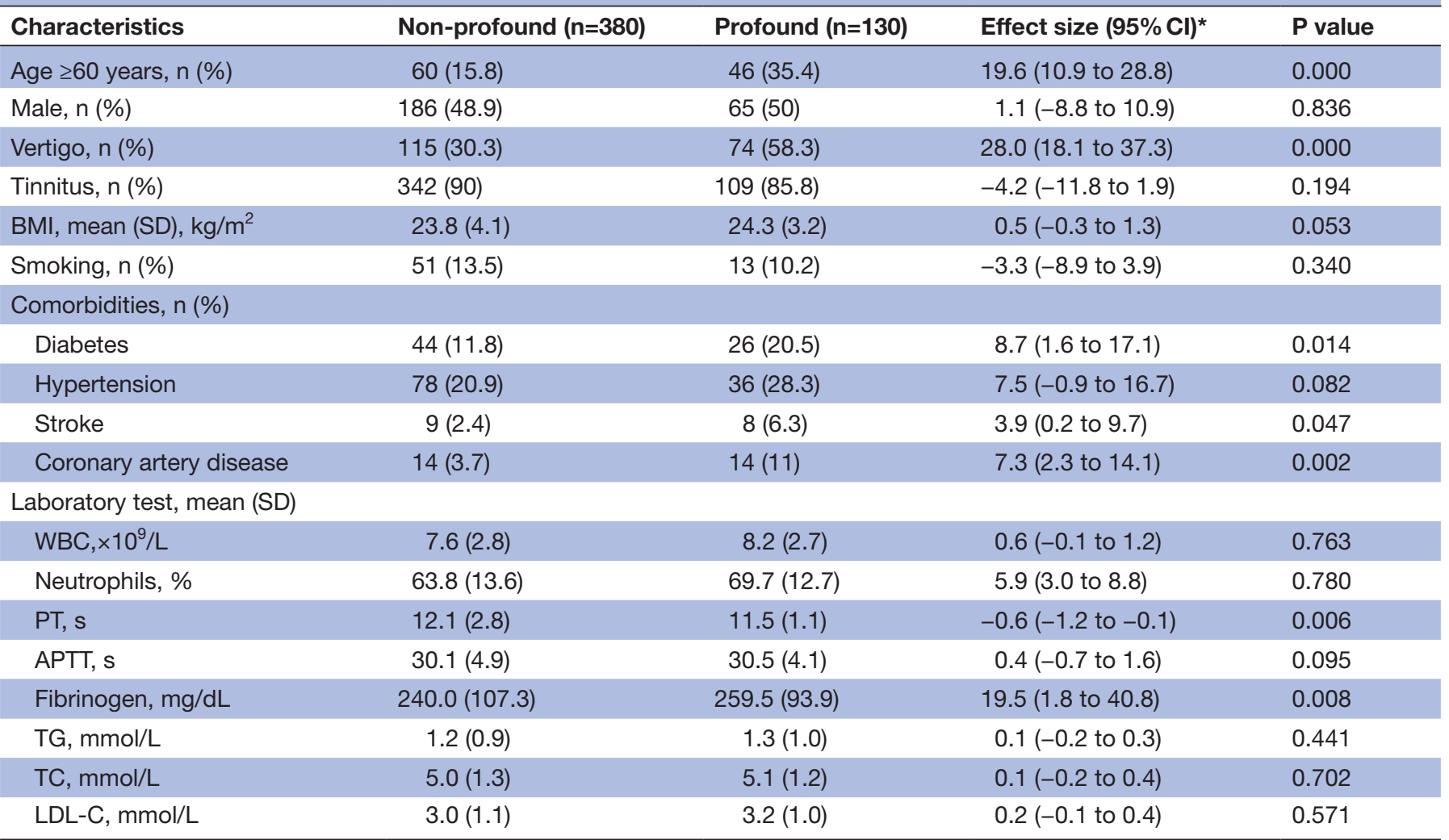

*Indicates mean difference for continuous variables and percentage difference for categorical variables.

APTT, activated partial thromboplastin time; BMI, body mass index; LDL-C, low-density lipoprotein cholesterol; PT, prothrombin time;

TC, total cholesterol; TG, triglyceride; WBC, white blood cell.

\section{DISCUSSION}

Weather conditions have long been recognised as an important factor in the deterioration of physical health since the time of Hippocrates (approximately $400 \mathrm{BC}$ ). ${ }^{13}$ Many studies have evaluated the association between SSNHL and weather and seasons. Mees $e t a l^{14}$ found that the incidence of SSNHL was significantly affected by atmospheric pressure. Herbert $e t a l^{15}$ also reported that the disease occurred more often at times of low pressure. Two retrospective studies from Korea demonstrated that the mean and maximum wind speeds were significantly and positively correlated with SSNHL onset. ${ }^{16} 17$ Concerning the seasonality of SSNHL, the results varied largely across studies. ${ }^{17-19}$ However, some studies have failed to establish a correlation between meteorological factors and the incidence ${ }^{20-22}$ and recovery rate of SSNHL. ${ }^{23}$ These studies mainly focused on the incidence and prognosis of SSNHL. Moreover, there are limited data on the relationship between the audiogram configurations of SSNHL and meteorological factors. This study showed that profound patterns were correlated with a high diurnal temperature range, while ascending patterns were correlated with high relative humidity. The study results did not indicate any correlation between seasons and audiogram configurations.

The positive association between profound patterns and the diurnal temperature range suggests that vascular factors may play a role in this subtype of SSNHL. The correlation between SSNHL and vascular disease is described in various studies. A prospective study by Lin et $a l^{24}$ reported that the risk of stroke within 5 years was 1.64 times higher in patients with SSNHL compared with those without SSNHL. In another 5-year follow-up study, Kuo et $a l^{25}$ collected data from 11115 patients with stroke and 33345 matched patients without stroke and reported that the incidence of SSNHL was

\begin{tabular}{|c|c|c|c|}
\hline Response to treatment, $\mathrm{n}(\%)$ & Non-profound $(n=250)$ & Profound $(n=123)$ & Effect size $(95 \% \mathrm{Cl})$ \\
\hline Complete recovery & $53(21.2)$ & $6(4.9)$ & $-16.3(-22.4$ to -9.2$)$ \\
\hline Slight improvement & $25(10)$ & $26(21.1)$ & 11.1 (3.5 to 19.8$)$ \\
\hline No improvement & $129(51.6)$ & $78(63.4)$ & $11.8(1.1$ to 21.9$)$ \\
\hline
\end{tabular}


approximately twice as high among patients with stroke than among those without stroke. In a previous study, the rapid change in ambient temperature had an effect on the overall stroke risk, and the effect was more immediate on ischaemic stroke than on intracerebral haemorrhage and subarachnoid haemorrhage. ${ }^{9}$ The change in temperature was also observed to be associated with an increased risk of overall and non-ST-elevation myocardial infarction. ${ }^{8}$ The effects of temperature change on SSNHL with a profound pattern and vascular-related diseases were similar. This similarity provides complementary evidence supporting that sudden hearing loss with a profound pattern is most likely of vascular origin, and the change in temperature may serve as a triggering factor for the interruption of microcirculation in the inner ear. When the temperature change overwhelms the adaptive capacity of the body, the sympathetic nervous system and renin-angiotensin system are activated, thereby resulting in vasoconstriction of the inner ear, accompanied by hyperviscosity, and leading to thromboembolism in some cases.

In addition, to vascular factors, the association between recent viral infection and SSNHL is established in a study. ${ }^{26}$ The seasonal pattern of viral infection is usually the result of its transmission under favourable meteorological conditions. Therefore, the virusinducing SSNHL theory cannot be ruled out. Recent studies have reported that severe acute respiratory syndrome coronavirus 2 (SARS-CoV-2) is a possible trigger of SSNHL. SARS-CoV-2 infection can promote microthrombosis in the inner ear by endotheliitis and cytokine activation. ${ }^{27}$

In addition, endolymph hydrops may be involved in the pathophysiology of SSNHL with an ascending pattern. The audiogram configurations mimic those observed in Ménière's disease. Schmidt et al reported that high humidity was strongly associated with a higher prevalence of initial attack and symptom exacerbation in Ménière's disease. ${ }^{28}$ In this study, the relative humidity was significantly higher on the day of onset in patients with ascending patterns. These findings further support the fact that SSNHL with an ascending pattern and Ménière's disease have a shared pathophysiology of endolymphatic hydrops.

This study also found that the risk factors of vascularrelated diseases overlap with the characteristics of patients with profound patterns, including older age; presence of vertigo; and history of diabetes mellitus, stroke and coronary artery disease. Moreover, a shorter prothrombin time and higher concentration of fibrinogen were observed in the group with profound patterns, which is associated with higher coagulation activity and blood viscosity. ${ }^{29}$ These results reinforce the presence of an underlying vascular problem in patients with SSNHL with profound patterns. SSNHL with a profound pattern can be disabling and has a considerable negative impact on the patient's quality of life. In this study, the recovery rate in the group with profound patterns was significantly lower than that in the other groups; therefore, there is a demand for an optimised treatment strategy. Given that vascular compromise may be the aetiology of SSNHL with a profound pattern, vasoactive and rheologic agents may be effective in the management of this particular group rather than of overall SSNHL. Some treatments based on vascular theory, such as fibrinogen/low-density lipoprotein apheresis $^{29}$ and local hypothermia, ${ }^{30}$ have been tested and have shown positive results. Further clinical trials are required to provide higher quality evidence.

This study has several limitations. First, as a retrospective study, data on onset time were primarily extracted from the medical records, which is based on the patients' self-report and may have introduced a recall bias. This study attempted to mitigate this limitation by including only those patients who were diagnosed with SSNHL within 14 days after SSNHL onset. Second, this study was conducted at only one hospital; therefore, more extensive multicentre studies are required.

\section{CONCLUSION}

The diurnal temperature range and relative humidity were associated with the audiogram configuration of SSNHL. A high diurnal temperature range on the day of SSNHL onset correlated with profound patterns, while high relative humidity on the day of SSNHL onset correlated with ascending patterns. However, there was no correlation between seasons and audiogram configurations.

Contributors JZ was tha guarantor and had full access to all the data in the study and takes responsibility for the integrity of the data and the accuracy of the data analysis. Concept and design: YJ, LY and JZ. Acquisition, analysis or interpretation of the data: All authors. Drafting of the manuscript: JZ. Critical revision of the manuscript for important intellectual content: YJ, LY and XM. Statistical analysis: JZ and SJ.

Funding This work was supported by Capital's Funds for Health Improvement and Research grant number 2020-2-4083.

\section{Competing interests None declared.}

Patient and public involvement Patients and/or the public were not involved in the design, or conduct, or reporting, or dissemination plans of this research.

Patient consent for publication Not applicable.

Ethics approval This study was approved by the Institutional Review Board of Peking University People's Hospital (reference number 2020PHB105-01).

Provenance and peer review Not commissioned; externally peer reviewed.

Data availability statement Data are available upon reasonable request. The meteorological data are available on the website of National Climatic Data Center (http://www.ncdc.noaa.gov/). Data of the enrolled patients will be shared by request from any qualified investigator.

Open access This is an open access article distributed in accordance with the Creative Commons Attribution Non Commercial (CC BY-NC 4.0) license, which permits others to distribute, remix, adapt, build upon this work non-commercially, and license their derivative works on different terms, provided the original work is properly cited, appropriate credit is given, any changes made indicated, and the use is non-commercial. See: http://creativecommons.org/licenses/by-nc/4.0/.

ORCID iD

Yuanyuan Jing http://orcid.org/0000-0003-2611-2409 


\section{REFERENCES}

1 Chandrasekhar SS, Tsai Do BS, Schwartz SR, et al. Clinical practice guideline: sudden hearing loss (update). Otolaryngol Head Neck Surg 2019;161:S1-45.

2 Byl FM. Sudden hearing loss: eight years' experience and suggested prognostic table. Laryngoscope 1984;94:647-61.

3 Simmons FB. Theory of membrane breaks in sudden hearing loss. Arch Otolaryngol 1968;88:41-8.

4 Chau JK, Lin JRJ, Atashband S, et al. Systematic review of the evidence for the etiology of adult sudden sensorineural hearing loss. Laryngoscope 2010;34

5 Kuhn M, Heman-Ackah SE, Shaikh JA, et al. Sudden sensorineural hearing loss: a review of diagnosis, treatment, and prognosis. Trends Amplif 2011;15:91-105.

6 Miller JM, Dengerink H. Control of inner ear blood flow. Am J Otolaryngol 1988;9:302-16

7 Ballesteros F, Alobid I, Tassies D, et al. Is there an overlap between sudden neurosensorial hearing loss and cardiovascular risk factors? Audiol Neurootol 2009;14:139-45.

8 Mohammad MA, Koul S, Rylance R, et al. Association of weather with day-to-day incidence of myocardial infarction: a SWEDEHEART nationwide observational study. JAMA Cardiol 2018;3:1081-9.

9 Lavados PM, Olavarría VV, Hoffmeister L. Ambient temperature and stroke risk: evidence supporting a short-term effect at a population level from acute environmental exposures. Stroke 2018;49:255-61.

10 Zebenholzer K, Rudel E, Frantal S, et al. Migraine and weather: a prospective diary-based analysis. Cephalalgia 2011;31:391-400.

11 Mattox DE, Simmons FB. Natural history of sudden sensorineura hearing loss. Ann Otol Rhinol Laryngol 1977;86:463-80.

12 Tran Ba Huy P. Idiopathic sudden sensorineural hearing loss. OtoRhino-Laryngologia Nova 1999;9:171-7.

13 Shutty MS, Cundiff G, DeGood DE. Pain complaint and the weather: weather sensitivity and symptom complaints in chronic pain patients. Pain 1992;49:199-204.

14 Mees K, Ruhenstroth-Bauer G, Sandhagen R, et al. [Idiopathic hearing loss-dependent on the weather?]. Laryngol Rhinol Otol 1987;66:246-8.

15 Herbert I, Nolte E, Eichhorn T. [Weather status and incidence of idiopathic facial nerve paralyses, vestibular disorders, Menière's attacks and sudden deafness]. Laryngol Rhinol Otol 1987;66:249-50.

16 Seo J-H, Jeon E-J, Park Y-S, et al. Meteorological conditions related to the onset of idiopathic sudden sensorineural hearing loss. Yonsei Med J 2014;55:1678-82.
17 Lee HM, Kim MS, Kim DJ, et al. Effects of meteorological factor and air pollution on sudden sensorineural hearing loss using the health claims data in Busan, Republic of Korea. Am J Otolaryngol 2019;40:393-9.

18 Wu C-S, Lin H-C, Chao P-Z. Sudden sensorineural hearing loss: evidence from Taiwan. Audiol Neurootol 2006;11:151-6.

19 Jourdy DN, Donatelli LA, Victor JD, et al. Assessment of variation throughout the year in the incidence of idiopathic sudden sensorineural hearing loss. Otol Neurotol 2010;31:53-7.

20 Lin H-C, Lee H-C, Chao P-Z, et al. The effects of weather on the incidence of sudden sensorineural hearing loss: a 5-year populationbased study. Audiol Neurootol 2006;11:165-71.

21 Danielides V, Nousia C-S, Bartzokas A, et al. Weather conditions and sudden sensorineural hearing loss. BMC Ear Nose Throat Disord 2002;2:2:2.

22 Mizukoshi K, Watanabe $\mathrm{Y}$, Shojaku $\mathrm{H}$, et al. Influence of a cold front upon the onset of Meniére's disease in Toyama, Japan. Acta Otolaryngol Suppl 1995;520 Pt 2:412-4.

23 Ryu IY, Park SH, Park EB, et al. Factors prognostic of seasonassociated sudden sensorineural hearing loss: a retrospective observational study. J Audiol Otol 2017:21:44-8.

24 Lin H-C, Chao P-Z, Lee H-C. Sudden sensorineural hearing loss increases the risk of stroke: a 5-year follow-up study. Stroke 2008;39:2744-8.

25 Kuo C-L, Shiao A-S, Wang S-J, et al. Risk of sudden sensorineural hearing loss in stroke patients: a 5-year nationwide investigation of 44,460 patients. Medicine 2016;95:e4841.

$26 \mathrm{Kim} \mathrm{SH}$, Kim S-J, Im H, et al. A trend in sudden sensorineural hearing loss: data from a population-based study. Audiol Neurootol 2017;22:311-6.

27 Harenberg J, Jonas JB, Trecca EMC. A liaison between sudden sensorineural hearing loss and SARS-CoV-2 infection. Thromb Haemost 2020;120:1237-9.

28 Schmidt W, Sarran C, Ronan N, et al. The weather and Ménière's disease: a longitudinal analysis in the UK. Otol Neurotol 2017;38:225-33.

29 Suckfüll M, Hearing Loss Study Group. Fibrinogen and LDL apheresis in treatment of sudden hearing loss: a randomised multicentre trial. Lancet 2002;360:1811-7.

30 Hato N, Hyodo J, Takeda S, et al. Local hypothermia in the treatment of idiopathic sudden sensorineural hearing loss. Auris Nasus Larynx 2010;37:626-30. 